\title{
Effectiveness of Video Assisted Teaching Programmeregarding Cervical Cancer And Its Preventive Measures On Knowledge Among Reproductive Age Group Women
}

\author{
${ }^{*}$ Mrs.Jassin Joseph, ${ }^{* *}$ Prof. Annie Annal M \& ${ }^{* * *}$ Mrs.UmaMaheswari R
}

\section{Abstract:}

Objectives: To assess the knowledge on cervical cancer and its preventive measures among reproductive age group women during pretest, to assess the effectiveness of video assisted teaching programme on cervical cancer and its preventive measures among reproductive age group women during post test, to find out the association between knowledge on cervical cancer and its preventive measures among reproductive age group women and selected demographic variables. Methods: Pre-experimental with One group pre-test - post-test design was adopted for the study. Result: The Study finding showed that $72 \%$ of them had inadequate knowledge, 28\% of them had moderately adequate knowledge and none of them had adequate knowledge about the cervical cancer and its preventive measures in the pretest. During post test no one had inadequate knowledge, $21.2 \%$ of them had moderately adequate knowledge and $78.8 \%$ of them had adequate knowledge about the cervical cancer and its preventive measures. Conclusion: The present study reveals that the proper video assisted teaching programme on cervical cancer and its preventive measures surely improves the knowledge on cervical cancer and its preventive measures which will prevent the early complications among reproductive age group women.

Keywords: Cervical Cancer, Preventive Measures, Reproductive age group women, video assisted teaching programme.

\section{INTRODUCTION}

Women are the second creator of the world after God. They are responsible for life on our planet earth. So being such an important creature, women and their health is an important issue. ${ }^{1}$ Cancer affects all communities worldwide, approximately ten million people diagnosed with cancer and more than six million die of the disease every year.20ne among the major cancers affecting the female community is cervical cancer. ${ }^{3}$ Cervical cancer is a disease of young women which commonly occurs around mid 40's.It can affect a wide age range and a women in 20's may develop the disease. Cervical cancer is the malignant cancer in cervical area. ${ }^{4}$ In India the National Cancer Registry Programme provides data on incidence and prevalence of cancer. ${ }^{6}$ It is estimated that new cases of gynecological cancers among women in India per year is 8.5 lakhs. Amongst them $23.5 \%$ cancer related death were due to cervical cancer. ${ }^{5}$ The early detection and prevention of cervical cancer is extremely critical in countries like India especially in rural areas, where due to lack of 
awareness, detection is delayed and they end up in advanced stages of cervical cancer which requires expensive treatments like chemotherapy and radiation therapy. ${ }^{7}$ Creating awareness among women will have an impact though it may not be apparent in the short term, but will be seen in long run. So the researcher has planned to assessed the lack of knowledge amongst reproductive age group women about cervical cancer and its preventive measures.

\section{OBJECTIVES:}

- To assess the knowledge regarding cervical cancer and its preventive measures On Knowledge among reproductive age group women during pretest.

- To assess the effectiveness of video assisted teaching programme on cervical cancer and its preventive measures among reproductive age group women during post test.

- To findout the association between knowledge on cervical cancer and its preventive measures among reproductive age group women and selected demographic variables.

\section{NULL HYPOTHESES:}

H01: There is no significant difference between pre test and post test knowledge on cervical cancer and its preventive measures among reproductive age group women after video assisted teaching programme.

H02: There is no significant association between pretest knowledge score with selected demographic variables such

\section{METHODOLOGY:}

Pre-experimental with One group pre-test - post-test design was adopted for the study to assess the knowledge on cervical cancer and its preventive measures, before and after administration of video assisted teaching programme on cervical cancer and its preventive measures. . The study was conducted in the rural areas under the Nettapakkam PHC, Puducherry. A total of 60 samples were selected by simple random sampling technique and data were collected by using structured knowledge questionnaire by interview method. Results were analyzed statistically using percentage, proportions and Chisquare test

\section{RESULT:}

\section{Assessment of the level of knowledge on cervical cancer and its preventive measures among reproductive age group women}

Finding showed that out of 60 samples most of them 43(72\%) had inadequate knowledge, 17(28\%) had moderately adequate knowledge.

The above table revealed that, the mean pre test knowledge score was 13 and post test knowledge score was 21,it was higher than the pre test .The standard deviation of pre test knowledge score 2.650 and post test knowledge score was 3.38.The obtained paried ' $\mathrm{t}$ ' value was 42.253 and $p$ value was 0.000.It was highly significant at $\mathrm{p}$ value $<0.001$ level.Hence the stated null hypothesis H01 was rejected.

In this study there is significant association between knowledge on cervical cancer and its preventive measures with age.Hence the stated null hypothesis $\mathrm{HO} 2$ was rejected. 
Effectiveness of video assisted teaching programme on cervical cancer and its preventive measures among reproductive age group women during post test.

\begin{tabular}{|c|c|c|c|c|c|c|}
\hline S.No & Variables & Mean & $\begin{array}{c}\text { Standard } \\
\text { Deviation }\end{array}$ & $\begin{array}{c}\text { Mean } \\
\text { difference }\end{array}$ & $\begin{array}{c}\text { Paired } \\
\text { 't' test }\end{array}$ & p value \\
\hline 1. & Pre test & 13 & 2.65 & \multirow{2}{*}{8.3} & 42.253 & $P=0.000^{* * *}$ \\
\cline { 1 - 4 } 2. & Post test & 21 & 3.38 & & \\
\hline
\end{tabular}

\section{CONCLUSION:}

The main aim of the present study confirms the effectiveness of video assisted teaching programme on cervical cancer and its preventive measures among reproductive age group women. The study reveals that the proper video assisted teaching programme on cervical cancer and its preventive measures which will prevent the early complications among reproductive age group women.

\section{REFERENCES:}

1. Cynda Ann Johnson.Women' S Health Care.1 st edition ,New Delhi: Jaypee Brothers;1998.

2. Ray $\mathrm{K}$,MandalS.Knowledge of endometrial cancer.Asia Pacific journal of cancer prevention,2005:18(21);21-22
3. ShwetaJoshi.Knowledge, attitude and practice of women on management of cervical cancer.Journal of Obstetrics and Gynaecology,2008;12(3):28-29

4. Connie HY.Cancer Nursing .6th edition ,Jones \&Barlett publishers;2005

5. MudaliarAL,Menon Krishna Mudaliar and Menon's clinical Gynaecology.10th edition , New Delhi:Orient Longman Private Limited; 2003

6. PolitF. Essential of Nursing Research,7th edition ,Philadelplhia, lippincot company 2006

7. DuttaDC.Textbook of Gynecology .5thedition;Calcutta:New Central Book Agency;2008

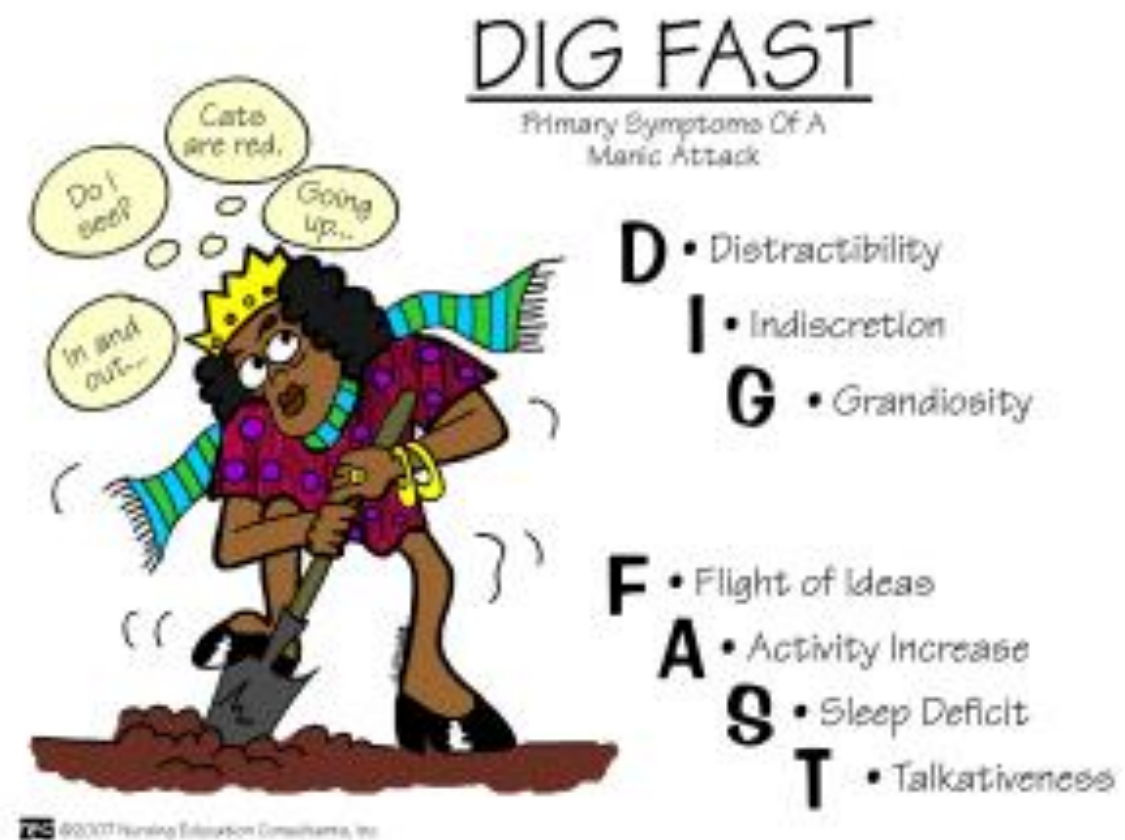

